\title{
Experience with Rectangular Titanium Cages in Anterior Cervical Discectomy and Fusion in a Single Unit of a Tertiary Level Hospital, Dhaka.
}

\author{
Islam $\mathrm{MJ}^{1}$, Ashadullah $\mathrm{ATM}^{2}$, Elahy $\mathrm{F}^{3}$, Uddin $\mathrm{KH}^{4}$, Ahamed $\mathrm{MU}^{5}$, Mondle $\mathrm{SZ}^{6}$, Ali $\mathrm{MM}^{7}$, Saha $\mathrm{SK}^{8}$,Asfia
} $\mathrm{KN}^{9}$, Rashid $\mathrm{MMH}^{10}$

Conflict of interest: There is no conflict of interest relevant to this paper to disclose.

Funding Agency : was not funded by any institute or any group.

Contribution of Authors : Principal

Investigator: Dr. Md. Joynul Islam

Manuscript preparation- Dr. Misbah

Uddin Ahmad, Dr. Md. Shamsuzzaman

Mondle, Dr. Md. Masum Ali, Dr. Sanat Kumar Saha.

Data collection- Dr. ATM Ashadullah

Dr. Fazle Elahy, Dr. Kazi Hafiz Uddin Editorial formatting- Dr. Kazi Nur Asfia, Prof. Dr. Mirza Md. Hafizur Rashid

Copyright: @2020bang.BJNS published by BSNS. This article is published under the creative commons CC-BY-NC license. This license permits use distribution (https://creativecommons. orgf/licences/by-nc/4-0/)reproduction in any medium, provided the original work is properly cited and is not used for commercial purposes

Received: 15.11 .2020

Accepted: 21.11.2020

\begin{abstract}
:
Background: Anterior cervical discectomy is a common procedure for treating patients for cervical disc prolapse. This study was conducted to evaluate the surgical outcome and demographic characteristics of patients who were treated for anterior cervical disc prolapse.

Methods: Study was conducted in the Department of Neurosurgery-spine, National Institute of Neurosciences and Hospital, Dhaka. Study interval was 5 years from January, 2014 to 31st December, 2019. Total numbers of patients were 215. Males were 183 (85.1\%) and females were 32 (14.9\%). All the patients had undergone the procedure of anterior cervical discectomy and fusion (ACDF) with RABEA Rectangular Titanium Cages (RTC). All the patients had plain MRI cervical spine done for diagnosis of anterior cervical disc prolapse. Surgical and Clinical preoperative evaluation and surgical outcomes were evaluated using pre- and postoperative Nurick, Visual Analog Scale (VAS), Neck Disability Index (NDI), for Myelopathy, overall Odoms outcome scores, postoperative surgical complications, and fusion and subsidence rates.
\end{abstract}

Results: Total 215 patients underwent ACDF; the mean age of these patients was 44.66 years, and their preoperative VAS and NDI, scores were 8.09 and 35.38 respectively. Sixty seven percent of patients had one level, $25.1 \%$ had two-level, and $7.9 \%$ had three-level procedures. On preoperative Magnetic Resonance Imaging(MRI), foraminal stenosis was present in $68.4 \%$ of patients, whereas medullar stenosis was present in $43.7 \%$. The rate of complications was $2.8 \%$ : two patients had postoperative implant migration (0.93\%), three patients had postoperative transient dysphagia (1.4\%) and one patients had temporary hoarseness of voice. Mean postoperative follow-up time was 6.7 months; postoperative VAS and NDI scores were 1.10 and 14.4, respectively. Postoperative fusion rate was $93.5 \%$, and subsidence rate was $5.6 \%$.

Conclusion: Results with Rectangular Titanium Cages are expectedly good. Symptoms resolved and fusion rate was $93.5 \%$ at 1 year follow up.

Keywords: Axial neck pain, cervical disc prolapse, Rectangular Titanium Cages(RTC), anterior cervical discectomy and fusion (ACDF)

Bang. J Neurosurgery 2021; 10(2): 137-147

1. Dr. Md. Joynul Islam, Associate Professor, Dept. of Clinical Neurosurgery, NINS

2. Dr. ATM Ashadullah, Associate Professor,Dept. of Neurosurgery-Spine, NINS ,

3. Dr. Fazle Elahy, Associate Professor, Dept. of Clinical Neurosurgery, NINS

4. Dr. Kazi Hafiz Uddin, Assistant Professor, Dept. of Clinical Neurosurgery, NINS

5. Dr. Misbah Uddin Ahmad, Assistant Professor, Dept. of Neurosurgery-Spine, NINS

6. Dr. Md. Shamsuzzaman Mondle, Assistant Professor, Dept. of Clinical Neurosurgery, NINS

7. Dr. Md. Masum Ali, Assistant Registrar, Dept. of Clinical Neurosurgery, NINS

8. Dr. Sanat Kumar Saha, Assistant Professor,Dept. of Neurosurgery,SSMC \& Mitford Hospital

9. Dr. Kazi Nur Asfia, Assistant Professor, Dept. of Neuroanesthesia, NINS

10. Prof. Dr. Mirza Md. Hafizur Rashid, Professor \& Head, Dept. of Neurosurgery, NINS

Address of Correspondence: Dr. Md. Joynul Islam, Associate Professor, Dept. of Clinical Neurosurgery, National Institute of Neurosciences (NINS), Dhaka, Bangladesh, Cell- +88 01711135961, email: joynul67@gmail.com 


\section{Introduction:}

Degenerative cervical myelopathy (DCM) is a progressive degenerative spine disease and the most common cause of spinal cord dysfunction in adults worldwide. ${ }^{1,2}$ The underlying pathophysiology involves age-related degeneration of the tissues of the spinal column, resulting in static spinal cord compression, and repetitive dynamic injury due to increased spinal column mobility ${ }^{1}$.With the average life expectancy increasing worldwide, it is understandable that in future the number of patients with Cervical Spondylotic Myelopathy(CSM) requiring medical attention will increase significantly ${ }^{2}$. According to the World Health Organization, the proportion of the population older than 60 years is projected to double from $11 \%$ in 2010 to $22 \%$ in $2050^{3}$. In the past decade, our understanding of the biomechanics of the spine has improved along with advances in spinal instrumentation. This has led to significant changes in the surgical management of DCM2. Although spinal degeneration is common in the elderly population, only a small portion will eventually develop myelopathy ${ }^{1}$.

Patients with significant spinal cord compression may present with common signs and symptoms of neurological dysfunction. The underlying degenerative spinal pathology may cause localized and radiating neck pain $n^{4,5}$. Neurological symptoms include paresthesia (numbness and tingling), abnormal gait/ balance and falls, decreased hand dexterity, and sphincter dysfunction. Concomitant radicular pain and weakness may also be present from spinal nerve root compression ${ }^{1}$.

There are two main methods of treating cervical disc prolapse, i.e., conservative and surgery. Conservative treatment consists of medicines, physical therapy and/ or bracing. The patient who is going to be a candidate for surgery will have radiological evidence of disc prolapse, significant weakness in the arms, arm pain worse than neck pain and patient not responding to the conservative treatment. It has shown that discectomy provide pain relief sooner than nonsurgical treatments. Anterior cervical discectomy is successful in comforting arm pain in $92-100 \%$ of people ${ }^{6}$.

Anterior cervical decompression and fusion (ACDF) is one of the most widely used surgical treatments for patients with cervical spondylosis ${ }^{7}$. ACDF achieves stabilisation and solid arthrodesis with good-toexcellent clinical outcomes and minimal surgical risks. The anterior approach to cervical decompression was first described by Cloward ${ }^{8}$, and Robinson and Smith ${ }^{9}$ in the 1950s. Both described an anterior approach via a longitudinal incision along the anterior border of the sternocleidomastoid muscle to allow for soft tissue dissection and annular incision. Following discectomy and removal of any compressive structure, fusion was then achieved using an autogenous graft ${ }^{10}$.

Several technical modifications have been developed, but no consensus regarding the optimal technique has been established. Interbody fusion following Anterior Cervical Discectomy (ACD) for treatment of cervical radiculopathy or cervical myelopathy is thought to have several advantages compared with discectomy alone. Controversy exists, however, regarding the optimal substrate for cervical fusion. The scarcity of randomized studies makes it difficult to establish a gold standard ${ }^{11}$.

During the last few years emerging strategies for the treatment of cervical disc disease (CDD) have been reported. Since different interbody fusion devices are now available, the controversy on the indication to perform microsurgical anterior cervical discectomy with fusion (ACDF) has been additionally accompanied with the discussion of selection of the material for the interbody spacer ${ }^{12}$.

There is no consensus, however, regarding the optimal substrate for cervical fusion. Autologous lliac Crest bone grafts (ICG) are used most commonly and yield fusion rates between $83 \%$ and $97 \%$. Bone graft harvesting at the iliac crest, however, results in additional pain and discomfort for the patient. Recently, rectangular titanium cages have been introduced as a new approach for fusion of the anterior cervical spine. Clinical experience thus far is limited ${ }^{13}$.

The introduction of Rectangular Titanium Cages(RTC) led in most studies to high success rates in terms of clinical outcome. Although the main advantage of titanium cages over autologous bone grafts is the lack of donor site morbidity, significant artifacts on computed tomography (CT) or Magnetic Resonance Imaging (MRI) constrain the postoperative assessment of the circumjacent structures. In our department ACD and Rectangular Titanium Cage (RTC) implantation was performed without additional filling as a routine procedure, showing fusion rates of nearly $100 \%$ (data not shown $)^{14}$.

In particular, RTCs are supposed to embody several theoretical advantages. Clinical experience, however, 
is limited. In a prospective non randomized controlled study of 36 patients, demonstrated that RTC fusion constitutes a safe and efficient.

The criteria required by a supreme bone substitute or device for cervical interbody fusion are the following: providing immediate stability in compression, resisting displacement, minimizing neck pain, maintaining spinal alignment and foraminal height, as well as higher or at least equal fusion success rate and clinical success rate, and obviating complications by using autograft ${ }^{15}$.

The aim of the present study was to evaluate the safety and effectiveness of Rectangular Titanium Cage (RTC) in terms of fusion of the operated segment and to examine the rate of cage subsidence and migration as well as clinical outcome in the treatment of Cervical disc disease.

\section{Method}

Patient cohort

The research used prospective observational study design and conducted in the Department of NeurosurgerySpine unit, National Institute of Neurosciences and Hospital, Dhaka, Bangladesh. The duration of the research was from January 2014 to December 2019. During this period a total of 215 patients underwent Anterior Cervical Discectomy and Fusion (ACDF). The study had approval from Ethical Review Committee of National Institute of Neurosciences (NINS).

The study respondents were included as consecutive series of patients with a one-,two-level or three-level Cervical Disc Disease (CDD) who underwent ACDF with implantation of a Rectangular Titanium Cage (RTC) during a 5-years period in study hospital. All patients had either clinical evidence of radiculopathy, myelo-radiculopathy, myelopathy or neck pain and failure of conservative treatment.

Inclusion criteria for the study population were: (1) signs and symptoms of cervical radiculopathy or spondylotic myelopathy, (2) cervical spondylosis confirmed using magnetic resonance imaging (MRI), and (3) follow-up of $\geq 3$ months. The patients who had (1) ossification of the posterior longitudinal ligament, (2) developmental stenosis, (3) invasive malignancy, (4) evidence of systemic or local infection, and (5) history of previous cervical spine surgery cage fillings with allo-, autograft or bone substitutes, additional plating for single/multiple-level ACDF or patients suffering from traumatic spinal cord injury, were excluded.

\section{Clinical evaluation and outcome scores}

Clinical preoperative evaluation and surgical outcomes were evaluated using pre- and postoperative Nurick and Visual Analog Scale (VAS) for neck and radicular pain as well as Neck Disability Index (NDI) score for myelopathy. The Plain X-ray of Cervical Spine (Both View) and the MRI of cervical spine were the main modality of investigation.Data were prospectively collected during the preoperative evaluation and also immediately collected after surgery as well as 3 months, and 12 months after surgery.

Study participants' demographic characteristics such as sex, age, level of CDD and duration of symptoms were collected preoepratively. The evaluation included presence of cervical and radicular pain, neurological deficits and working capacity and disability and radiological in terms of fusion of the operated segment and to examine the rate of cage subsidence.

The overall clinical outcome was assessed during discharge, at 3 , and 12 months using 'Odom's criteria' as follows: excellent (complete relief of symptoms without impairment in daily activity); good (intermittent remaining symptoms, but normal daily activities); fair (subjective improvement of symptoms, but impaired daily activity); and poor (no improvement or worsening of the symptoms).

\section{Surgical Procedures}

All patients underwent Anterior Cervical Discectomy (ACD) in which standard microsurgical techniques were used. Surgical procedures were conducted using the common anterolateral approach according to Smith and Robinson via a right-sided skin incision under general anaesthesia. The posterior longitudinal ligament was excised thoroughly and foraminal decompression was performed bilaterally to ensure adequate neural decompression. Gentle decortication of the endplates was undertaken using a curette. Great care was taken to remove the cartilaginous tissue, but preserve intact endplates. No drill was used for the preparation of the endplates

The Rectangular Titanium Cage (RTC) were inserted into the intervertebral space. The size and shape of the cage were selected based on both the preoperative imaging studies and the intraoperative measurements. Typically the cage heights were 5 to $7 \mathrm{~mm}$. The cages were not filled with bone or other material. The surgeons 
were experienced with implants and performed the operation of patients. The vast majority of procedures were performed by two of the authors (J.I and A.U.). Postoperatively, all patients were treated by the same protocol, which consisted of physical rest for 6 weeks and then physical therapy. A cervical collar was applied for 6 weeks.

\section{Radiological evaluation}

Radiographic examinations included pre- and post operative plain and functional radiography. Anteroposterior, lateral, and flexion-extension cervical radiographs were obtained before and immediately after surgery, as well as at 3 and 12 months after surgery (Fig. 1,Figure.2). MRI evaluation was preoperatively performed in all patients. Signs of medullar and radicular compression, and myelopathy signs were analyzed.

Postoperative radiographs were analyzed for fusion, subsidence and migration. Fusion was defined as (1) movement $<2^{\circ}$ in postoperative flexion-extension radiographs, (2) presence of trabeculae bridging bone postoperative images.
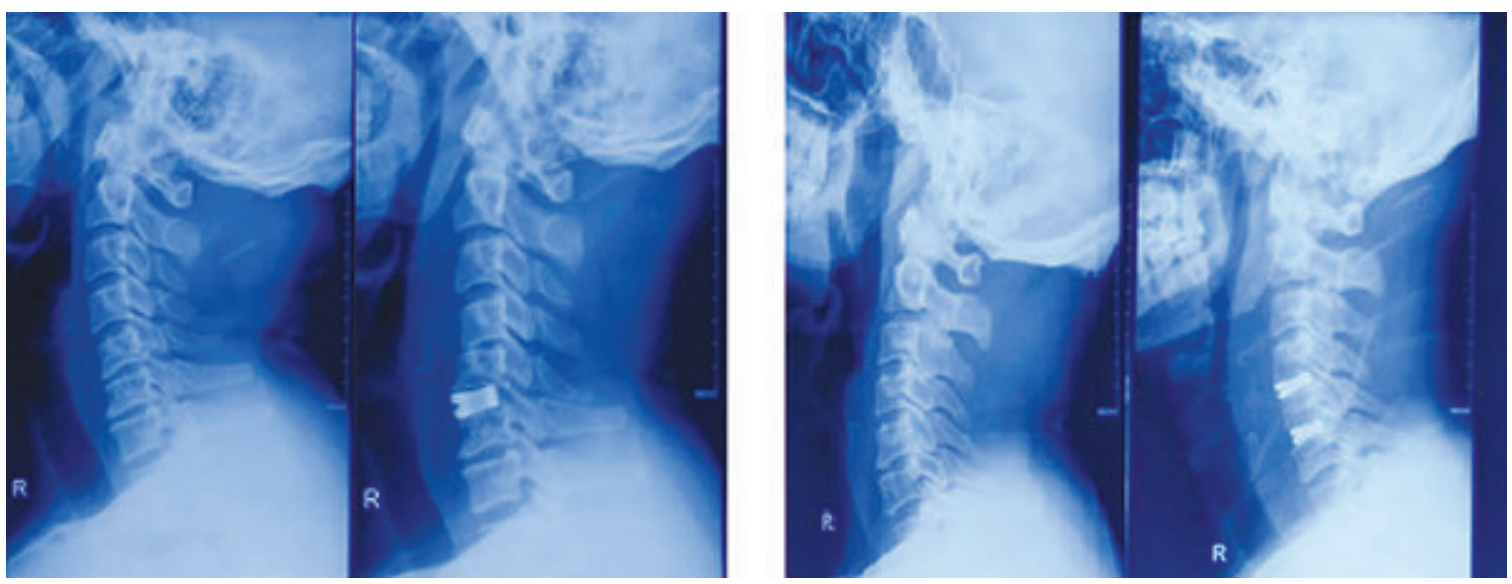

Fig. -1. Lateral cervical spine X-ray (A) Single Level immediately post operative day after anterior cervical discectomy with fusion at level C6/7 with Titanium cage. (B) Two Level : immediately post operative day after anterior cervical discectomy with fusion at level C5/6, 6/7 with Titanium cage.
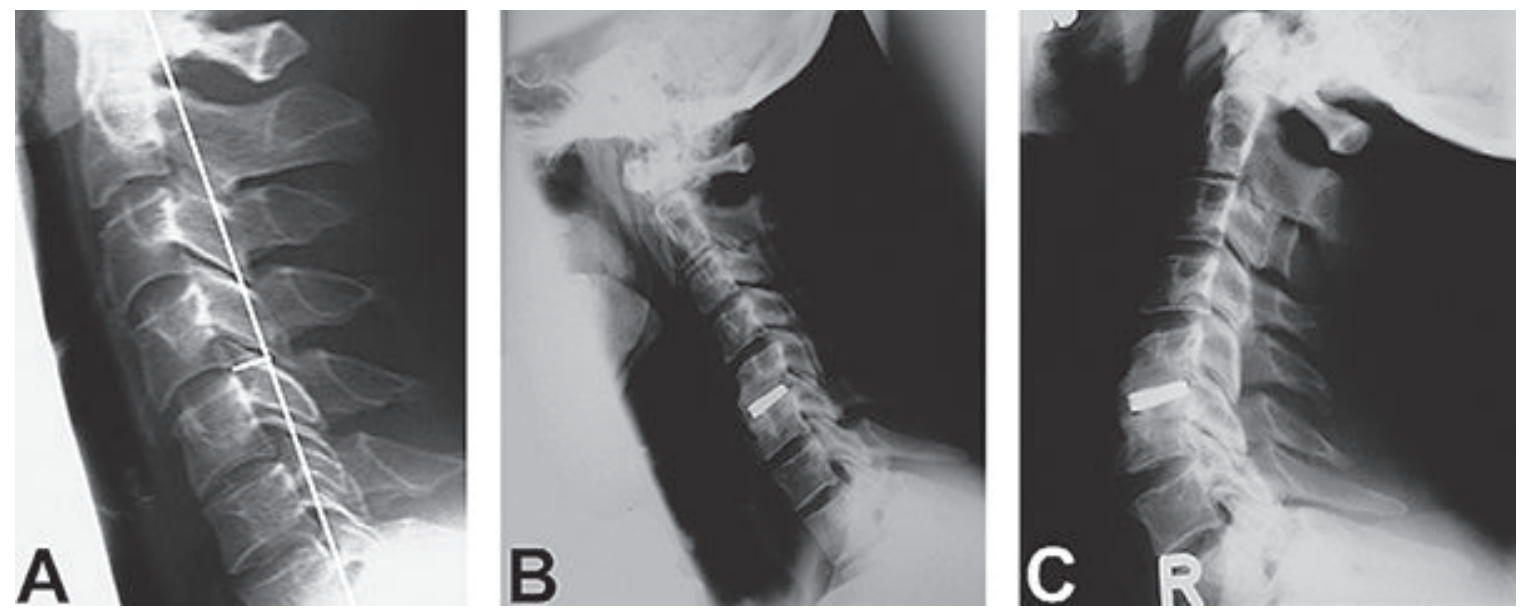

Fig. -2. Lateral cervical spine $X$-ray (A) Measurement for evaluation of lordosis. (B and $C$ ) showing functional flflexion/extension radiographic views at 12- month interval after anterior cervical discectomy with fusion at level C5/6 with Titanium cage. Absence of segmental motion and presence of bony bridges were documented in this patient. 
Standard radiographs were assessed to determine the presence of intersegmental bridging bone. Because metal cages do not allow the growth of bone through the implant to be determined, stability was also assessed using an overlay method of the flexionextension radiographs and by measuring the distance between the spinous processes.12 Each surgically treated segment was deemed fused if there was obvious bridging bone, if there was less than $2 U$ of segmental motion, and if the interspinous distance did not change by more than $2 \mathrm{~mm}$. Two degrees and $2 \mathrm{~mm}$ of motion were used as the upper limits to compensate for measurement and radiographic projection error. If there was a lucent line at the implant's margin(s), the segment was considered to be unfused regardless of the aforementioned measurements.

In patients in whom bisegmental surgery was performed, the mass was categorized as fused only if both levels met the aforementioned criteria. To assess loss of segmental height over time, subsidence or collapse of the implant was measured and considered significant if greater than $2 \mathrm{~mm}$.

Migration into the adjacent VB exceeding $2 \mathrm{~mm}$ was considered to reflect a pathological complication. Two categories were used: moderate $(<4 \mathrm{~mm})$ and severe $(>4 \mathrm{~mm})$. This semiquantitative grading of migration was an attempt to address cage movement in relation to the adjacent VBs. Therefore, the term cage migration was used to differentiate this type of change from subsidence11.

\section{Rectangular Titanium Cage}

In this study, RABEA Rectangular Titanium Cages (MJ Surgical,Ahmedabad, India) were used. The device is produced from forged titanium alloy (MR imaging compatible), has a cuboid form, toothed spikes cranially and caudally, is hollow, and the upper and lower surfaces have 1-mm toothed spikes that assist in the positive anchorage of the implant between the Vertebral Bodies. (Fig.3). The RABEA Rectangular Titanium Cages spinal implant is approved by the Food and Drug Administration for use in humans as a spinal intervertebral body fusion device 12 .

\section{Statistical analysis}

Descriptive statistics were used to describe epidemiological and clinical data. Fisher's c2 , Kruskall-Wallis and Student t-tests were used for univariate analysis. Statistical analyses were performed using IBM SPSS Statistics ver. 18.0 (IBM Corp., Armonk, NY, USA).
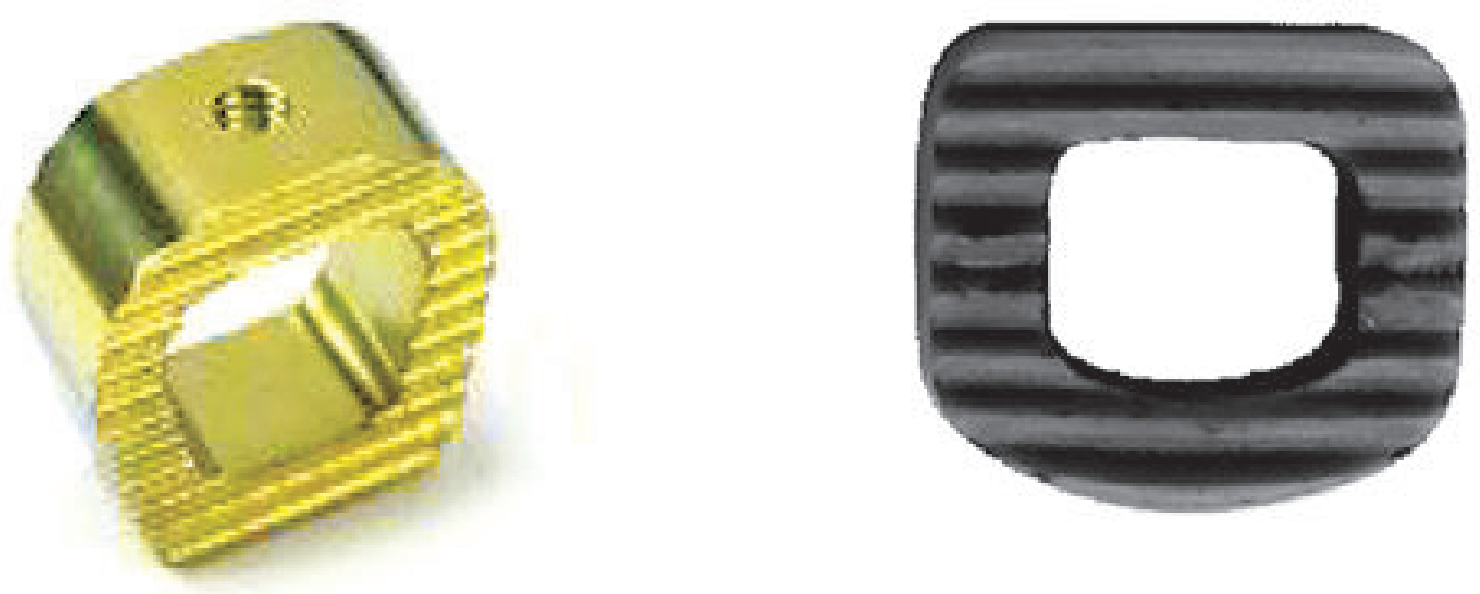

Fig.-3: RABEA Rectangular Titanium Cages (MJ Surgical,Ahmedabad,India) 


\section{Result:}

1. Patients

Our analysis included a total of 215 patients who met the inclusion criteria for this study. The average age of the patients was 44.66 years; they had cervical or radicular symptoms for a period of approximately 18.4 months, and a follow-up time of 6.7 months. Thirtytwo patients (14.9\%) were female, and $183(85.1 \%)$ patients were male with a female to male ratio of $1: 6.71$ (Table 1).

Table-I Clinical and epidemiological data

\begin{tabular}{lcc}
\hline No. of patients & 215 & \\
Age $(\mathrm{yr})$ & 44.66 & \\
Gender & & \\
Female & 32 & $(14.9)$ \\
Male & 183 & $(85.1)$ \\
Time with symptoms (mo) & $18.40 \pm$ & \\
Level & & \\
Single level & 144 & $(67.0)$ \\
Two levels & 54 & $(25.1)$ \\
Three levels & 17 & $(7.9)$ \\
Type of pain & & \\
Cervical & 65 & $(30.2)$ \\
Radicular & 31 & $(14.4)$ \\
Both & 119 & $(55.3)$ \\
Nurick score & & \\
0 & 85 & $(39.5)$ \\
1 & 85 & $(39.5)$ \\
2 & 23 & $(10.7)$ \\
3 & 11 & $(5.1)$ \\
4 & 8 & $(3.7)$ \\
5 & 3 & $(1.4)$ \\
Radiological findings & & \\
Lordotic Change & & 79.2 \\
Listhesis & & \\
Foraminal stenosis & 147 & $(68.4)$ \\
Central stenosis & 94 & $(43.7)$ \\
Cervical myelopathy & 59 & $(27.4)$ \\
\hline
\end{tabular}

In preoperative clinical evaluation, $30.2 \%$ of patients reported cervical pain, $14.4 \%$ reported radicular pain, and $55.3 \%$ reported both; mean preoperative VAS pain score was 8.09 , with a mean NDI score of 35.38 (81.1\% of patients had at least moderate disability). Myelopathic symptoms were present in $39.5 \%$ of patients; $39.5 \%$ of patients had Nurick 1 myelopathy (Table 2).
One hundred sixty eight patients $(68.4 \%)$ had central cervical stenosis; only $27.4 \%$ had signs of medullar myelopathy on MRI. On lateral X-ray, $79.2 \%$ of patients had lordotic preoperative cervical curvature (Table 1).

\section{Clinical outcome}

$40 \%$ (86) of the patients rated an excellent, $52 \%$ (112) of the patients rated good and $8 \%(17)$ of the patients rated fair during the follow-up after 3 months. After 1year follow-up, 58\% (125) of the patients found an excellent,38\% (82) of the patients found good and $04 \%$ (08) of the patients rated fair (Table.3). Clinical outcome was not affected by cage subsidence ( $p>$ $0.211)$ or presence of bone formation $(p>0.410)$.

ACDF was performed at one-level in $67 \%$ of patients , at two-level in $25.1 \%$ of patients, and at three-level in $7.9 \%$ of patients. Six patients $(2.8 \%)$ developed postoperative complications two patients had postoperative implant migration $(0.93 \%)$, three patients had post operative transient dysphagia (1.4\%) and one patients had temporary hoarseness of voice.

On follow-up, all patients reported at least partial improvement in functional status and pain scale; VAS score improved from 8.09 to 1.1 and NDI score improved from 35.38 to 14.44 . All scales exhibited statistically significant improvement (pd"0.001). No significant difference was found between single versus multilevel disease in clinical outcome (VAS or NDI); (Table 2).

Table-II

Clinical and surgical outcome

\begin{tabular}{lc}
\hline Variable & Mean \pm standard deviation \\
\hline NDI (\%) & \\
Preop & $35.38 \pm 2.93$ \\
Postop & $14.44 \pm 2.91$ \\
VAS score & \\
Preop & $8.09 \pm 5.7$ \\
Postop & $1.10 \pm 0.89$ \\
Complications & $6 \pm 2.8$ \\
Fusion rate (\%) & 93.5 \\
Single level & 96.26 \\
Multilevel & 88.89 \\
Subsidence rate (\%) & 5.6 \\
Single level & 41.67 \\
Multilevel & 58.33 \\
Adjacent Segment Change (\%) & 17 \\
\hline
\end{tabular}


Table-III

Outcome Accroding to Odoms Criteria

\begin{tabular}{lcc}
\hline Odoms criteria & 3 month & 12 month \\
\hline Excellent & $40 \%(86)$ & $58 \%(125)$ \\
Good & $52 \%(112)$ & $38 \%(82)$ \\
Fair & $8 \%(07)$ & $04 \%(08)$ \\
Poor & & \\
\hline
\end{tabular}

\section{Radiological outcome}

Fusion was documented in $93.5 \%$ of patients (Fig. $4 \mathrm{~A}) ; 96.26 \%$ of patients with single level disease achieved post operative fusion versus $88.9 \%$ of patients with multilevel disease.

There was a significant difference between the single and multilevel disease groups $(p=0.04)$. (Table 2$)$.

Cage subsidence was found in twelve patients ( $5.6 \%$ ) with no significant difference between single or multilevel procedures. Two methods of addressing

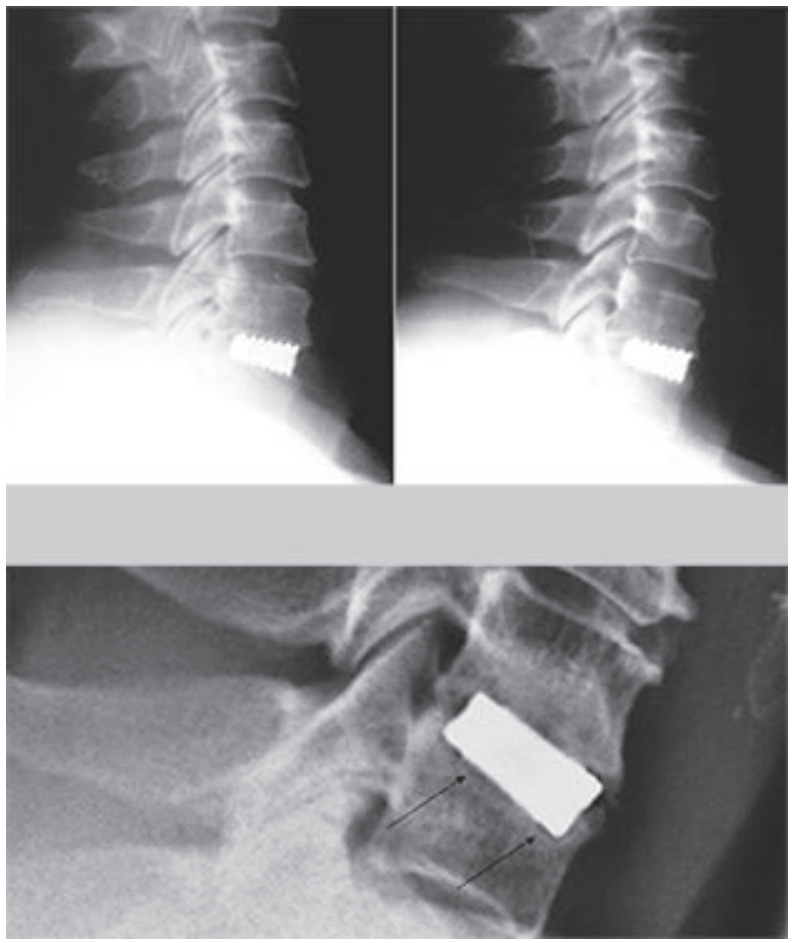

Fig.-4: (A) Postoperative lateral radiograph of a patient with C6-7 disc herniation grafting by a $8 \mathrm{~mm}$ cage. (B) One-year follow-up radiograph revealed maintenance of disc height and successful fusion. (C) A radiolucent gap can be seen in both cases around the cage (arrows). cage movement and subsidence were used. One consisted of a semiquantitative measuring method in which the known cage height was used as a reference. Subsidence was measured according to the method proposed by Gercek, et al In their scheme, cage movement is viewed indirectly in relation to the measured changes of the disc space (Fig. 4 C). All calculations were made on the lateral plain radiographs at discharge and at follow-up examination 3 months and 1 year later

We observed that nine patients $(17 \%)$ had adjacent segment changes in follow-up studies, but none had symptomatology attributable to the findings identified using imaging (Fig.1A). No significant differences were found in adjacent segment changes between patients with single level or multilevel procedures. At followup, there was no significant difference in clinical outcome between patients with adjacent segment changes and patients with any findings in sequential image studies (Table 2)

\subsection{Complications}

The rate of complications was $2.8 \%$ : two patients had postoperative implant migration $(0.93 \%)$, three patients had post operative transient dysphagia (1.4\%) and one patients had temporary hoarseness of voice. The radiological and clinical postoperative follow-up was uneventful and the patient remained asymptomatic.

\section{Discussion:}

The anterior approach to cervical decompression was first described by Cloward ${ }^{8}$ and Robinson and Smith $^{9}$ in the 1950s. Since its introduction by Cloward and by Smith and Robinson, the anterior cervical microsurgical approach has become established as the procedure of choice for the treatment of disc herniation and spondylosis ${ }^{16}$.

The ideal cervical fusion substitute would result in fusion in all patients and offer maximal comfort. It would avoid pain at autograft sites and associated soft tissue morbidity, obviate the need for cervical orthosis, and not impair subsequent radiologic investigations. It would provide immediate stability in compression and resist axial displacement, minimize neck pain, and maintain spinal alignment and foraminal height.All these demands led many authors in recent years to study fusion cages. ${ }^{13}$

In accordance with the preference often given to SmithRobinson fusion, rectangular cages are supposed to combine several theoretical advantages. They are 
thought to provide immediate stability, maintain a constant height, improve cervical lordosis, have a lower profile than plates, carry no infectious risk, and require no bone graft harvesting. ${ }^{17}$

The rectangular titanium RABEA cage (MJ Surgical,Ahmedabad,India) used in the present study is characterized by additional spikes, which are supposed to be autostabilizing, and thus additional platebased immobilization is thought to be unnecessary. Because cages are sunk just below the vertebral surface, they essentially represent a so-called no-profile device for stabilization. An interface with the esophagus, which is common to all plate devices and which may provoke dysphagia, is not present with cages. Pilot studies of the RABEA cage conducted by $\mathrm{Al}-\mathrm{Hami}{ }^{18}$ and Lange, et al. ${ }^{19}$ have yielded promising results.

Anterior Plate Constructs(APC) for ACDF are effective in achieving immediate stability, improving cervical sagittal alignment, and increasing fusion rates, with a low profile of current anterior plating systems. More recently, there has been an increase in the use of the Rectangular Titanium Cage (RTC), which does not require an anterior plate and minimizes cervical soft tissue disruption, thereby reducing the profile of the construct ${ }^{20}$. Studies have demonstrated the safety and efficacy of three-level ACDF with cages and plate fixation; however, complications associated with plate fixation (e.g., breakage, loosening of screws, screw penetration to endplate, triangle fracture, and visceral and vascular structural injuries) have been reported with multilevel ACDF. ${ }^{21}$ RectangularTitanium cages (RTC) appear to overcome these limitations of anterior plating, but there is disagreement regarding the use of Rectangular Titanium cages (RTC) with respect to subsidence, cage migration, loss of cervical lordosis and fused segment angle, and relatively low fusion rate. ${ }^{22}$ Some studies have indicated that RTC has a better clinical effect on cervical spondylosis, with fewer invasive surgical treatments than APC. ${ }^{23}$ The surgical procedure for RTC is very simple and relatively short ${ }^{24}$. The operative time is significantly greater and blood loss is significantly higher with APC, compared with RTC, in single and multilevel procedures. $25,26,27$ Surgical exposure and steps for plate insertion are time-consuming and increase soft tissue dissection, blood loss, and surgical time. We achieved excellent results with RTC for single and multilevel disease (Fig.4), with significant improvement in NDI and VAS scores. Clinical results in pain and functional scales between preoperative and postoperative groups of patients were improved in this case series. Few previous reports have addressed the comparison between single and multilevel cervical disease in the same case series. In this study, we found that clinical and radiological outcomes were significant improvement between the preoperative and postoperative groups. APC might pose a substantial risk of hardware-related complications, such as plate dislodgement, soft tissue injury, tracheoesophageal lesions, and dysphagia ${ }^{28,29}$. Dysphagia is recognized as the earliest complaint after ACDF using an additional anterior plate. The reported incidence of transient dysphagia after ACDF ranges from $2 \%-71 \%$, and that of chronic dysphagia ranges from $3 \%-21 \% .{ }^{28}$ Studies have found that RTC has a lower risk of dysphagia as a complication, compared with APC, in postoperative and follow-up periods. ${ }^{20} \mathrm{Li}$ et al. ${ }^{32}$ reported a $6.8 \%$ incidence of postoperative dysphagia, as well as $2.8 \%$ incidence at 3 months postoperatively.

We observed a $1.4 \%$ incidence of transient dysphagia that lasted 4-7 days, less than that reported with the APC technique; notably, no patients exhibited permanent dysphagia. Dysphagia following instrumentation with APC implies that plate design may have an effect on soft tissue structures; possible explanations include postoperative soft tissue edema, esophageal injury, postoperative hematoma, and adhesive formations around implanted cervical plates. ${ }^{33}$ Low-profile implants are completely contained in the intervertebral space, avoiding mechanical stimulus to the esophagus; furthermore, the operative procedure is simpler, with reduced retraction of the esophagus, diminishing the risk of postoperative dysphagia. ${ }^{34}$ Patients undergoing threelevel fusion have significantly higher incidence of postoperative dysphagia than those undergoing oneor two-level fusions, because of the iatrogenic irritation to soft tissues during surgical exposure; ${ }^{35}$ therefore, we recommend gentle dissection of cervical tissues and adequate surgical level planning to reduce the incidence of postoperative complications related to the procedure.

Only stable bony fusion prevents delayed kyphotic deformity with concomitant foraminal stenosis causing root compression and neck pain. When single-level ACDF is performed, $83 \%-100 \%$ of radiographic fusion is reported with both techniques. ${ }^{32}$ In multilevel cervical 
disease, bony fusion rates and postoperative sagittal balance have varied among studies as well as on the basis of parameters used for evaluation; fusion rates for multilevel cervical disc degenerative disease vary from $78 \%-100 \% .{ }^{21,37}$ Chen et al. ${ }^{21}$ reported similar rates of fusion between both techniques (APC versus RTC) in multilevel cervical disease $(95.7 \%$ versus $92.3 \%)$. We observed total fusion in $93.5 \%$ of patients (Fig. 2A), with significantly higher rates of fusion in the single level procedure than in multilevel surgery (96.26\% versus $88.9 \%)$; however, there was no significant difference in clinical outcome between both groups. Long-term results must be evaluated, and other factors beyond technique should be considered during evaluation; these include bone quality of the patients, implant used, distraction achieved by cage usage, and grade of subchondral bone exposure during the meticulous preparation of the endplate for fusion.

During the process of bone remodeling, the settlement of the cage of $<2 \mathrm{~mm}$ into the vertebral bodies until fusion is to be expected; subsidence is defined as the sinking of an object with a greater elasticity modulus (cage) into an object with a lower elasticity modulus (vertebral body). ${ }^{36}$ If the cage subsides into the vertebral body with disc space collapse, foraminal height and cervical alignment are not restored. 22,28 Subsidence has been reported in 9.3 to $62.5 \%$ of cervical segments analyzed, and it often occurs within 3 months after surgery $22,28,37-39$. Although subsidence does not appear to affect clinical outcomes, this must be evaluated in long-term studies. ${ }^{21,40-42}$ We observed cage subsidence in $5.6 \%$ of our patients, that was within the range reported in previous series. In a onelevel procedure, no significant difference was present between the two techniques, and subsidence risk increased with the number of levels treated; it was more common in C5-6 and C6-7 levels, as we observed in the present study. ${ }^{36,20}$ With a greater increase in interbody height, the risk for subsidence also increases, suggesting that oversized cages may be a risk factor for subsidence; ${ }^{36}$ we found no significant difference in the incidence of subsidence between single and multilevel procedures. Nevertheless, the long-term clinical outcome of patients with subsidence remains satisfactory, as the disc height of treated level at final follow-up remains significantly greater that that before surgery; moreover, after fusion, subsidence does not progress ${ }^{36,32,43}$. Kao et al. ${ }^{36}$ reported no subsidence-related symptoms that required treatment during follow-up in a series of patients treated with RTC for cervical disc disease. In our series, we found no difference in clinical outcome evaluated by NDI and VAS between subsidence and no-subsidence groups. There are no objective parameters for use in determining the correct size cage or predicting clinical outcome. ${ }^{36,44}$ Sagittal misalignment will cause an increased stress distribution on internal fixation devices, as well as cervical instability, postoperative axial pain, and deterioration of neurological deficit; these parameters influence functional recovery ${ }^{32}$. In addition, maintenance of cervical alignment is important because malalignment leads to adjacent segmental degeneration of the fused segment and can also cause worsening of long-term outcomes. ${ }^{37}$ We observed improvement in cervical lordosis of $5.7^{\circ}$ without significant difference between single and multilevel disease. Both APC and RTC improved local and global sagittal balance in single and multilevel cervical degenerative disease; some studies have shown no significant differences in cervical angles between these techniques. ${ }^{20,29}$ Incidence of adjacent segment disease following ACDF has been reported in approximately $25 \%$ of patients 45 Peri-plate ossification has been previously described as a finding following arthrodesis with anterior cervical plate; notably, there is a higher incidence of adjacent segment degeneration if an additional plate is placed close to an adjacent disc space ${ }^{29}$. With RTC, the incidence of adjacent segment disease is reported from $2 \%$ to $30 \% \%$ at follow-up ${ }^{32}$. We found adjacent segment changes in sequential postoperative studies in forty thirty seven patients ( $17 \%$ ), with no difference between single and multilevel disease; moreover, there was no difference in clinical outcome (Fig. 1A,B). These findings suggest that even with the RTC technique, there is a significant risk of adjacent segment disease, and additional follow-up is needed to evaluate clinical outcome related to adjacent segment changes in imaging studies.

\section{Bone formation}

The higher rate of bone formation in our study patients with RTC could be explained by three factors: 1 . The patients were younger and could possibly muster larger osteogenic abilities. 2. The Plasmapore coating of the RTC-cages enlarges the surface and might increase osteoconductive properties. 3. Cage subsidence and subsequent exposure of cancellous bone inside the cage might promote fusion in certain 
case. The fusion rate of empty Rectangular Titanium Cages is reported to reach even 100 and occur as the result of endplate failure and subsequent filling of a cage by fracture fragments. ${ }^{46}$

Case-control studies involving patients surgically treated with ACDF via RTC versus APC technique are needed; furthermore, long-term consequences of complications (e.g., subsidence, sagittal misalignment, adjacent segment disease, and pseudoarthrosis) must be addressed for further analysis of clinical and radiological results.

\section{Conclusion:}

The results of our study suggest that RTCs are a safe and effective alternative to bone autografts after ACD for treatment of cervical disc disease. ACDF with Rectangular Titanium Cage cervical devices is an excellent option for cervical degenerative disc disease of one, two, and three levels; similar results were reported with ACDF using either a stand alone cage or a plate.

\section{References:}

1. Michael G. Fehlings,,Lindsay A. Tetreault, K. Daniel RiewJames, W. Middleton, Jeffrey C. Wang,2017 A Clinical Practice Guideline for the Management of Degenerative Cervical Myelopathy: Introduction, Rationale, and Scope Global Spine Journal, Vol. 7(3S) 21S-27S

2. N. Muthukumar.Surgical management of cervical spondylotic myelopathy. Neurology India.2012,Vol 60,| Issue 2

3. Fehlings MG, Tetreault L, Nater A, et al. The aging of the global population: the changing epidemiology of disease and spinal disorders. Neurosurgery. 2015;77(suppl 4):S1S5. doi:10.1227/ NEU.0000000000000953.

4. Kalsi-Ryan S, Karadimas SK, Fehlings MG.2013 Cervical spondylotic myelopathy: the clinical phenomenon and the current pathobiology of an increasingly prevalent and devastating disorder. Neuroscientist.19:409-421

5. Tracy JA, Bartleson JD.2010 Cervical spondylotic myelopathy. Neurologist.16:176-187.

6. Muhammad Junaid, Mamoon Ur Rashid, Afeera Afsheen, Syed Sarmad Bukhari, Anisa Kalsoom Experience with Titanium Cages in Anterior Cervical Discectomy and Fusion, J Ayub Med Coll Abbottabad 2016;28(1)

7. Fountas KN, Kapsalaki EZ, Nikolakakos LG, Smisson HF, Johnston KW, Grigorian AA, et al. Anterior cervical discectomy and fusion associated complications. Spine. 2007;32(21)):2310-7. 2310.1097/ BRS.2310b2013e318154c318157e.

8. Cloward RB. The anterior approach for removal of ruptured cervical disks. J Neurosurg. 1958;15(6):602-17.

9. Smith GW, Robinson RA. The treatment of certain cervicalspine disorders by anterior removal of the intervertebral disc and interbody fusion. J Bone Joint Surg. 1958;40(3):607-24.

10. Elizabeth Chong, Matthew H Pelletier, Ralph J Mobbs, William R Walsh.The design evolution of interbody cages in anterior cervical discectomy and fusion: a systematic review.BMC Musculoskeletal Disorders 2015; 10.1186/ s12891-015-0546-x

11. Claudius Thome, Olaf Leheta,Joachim K. Krauss, Dimitris Zevgaridis. A prospective randomized comparison of rectangular titanium cage fusion and iliac crest autograft fusion in patients undergoing anterior cervical discectomy.J Neurosurg Spine 2006; 4:1-9,

12. Niklaus Krayenbuhl, Christian Schneider, Hans Landolt, Javier Fandino. Clinical Study Use of an empty, plasmaporecovered titanium cage for interbody fusion after anterior cervical microdiscectomy Journal of Clinical Neuroscience 15 (2008) 11-17

13. Claudius Thome, Joachim K. Krauss, Dimitris Zevgaridis. A prospective clinical comparison of rectangular titanium cages and iliac crest autografts in anterior cervical discectomy and fusion Neurosurg Rev (2004) 27:34-41

14. Ioannis Pechlivanis, Theresa Thuring, Christopher Brenke, Marcel Seiz, Claudius Thome, Martin Barth, Albrecht Harders,Kirsten Schmieder.Non-Fusion Rates in Anterior Cervical Discectomy and Implantation of Empty Polyetheretherketone Cages SPINE 2010 Volume 36, Number 1, pp 15-20

15. Chi-Chien Niu, Lih-Huei Chen, Po-Liang Lai, Tsai-Sheng Fu,Wen-Jer Chen.Trapezoidal Titanium Cage in Anterior Cervical Interbody Fusion: A Clinical Experience. Chang Gung Med J 2005;28:212-21

16. Claudius Thome, Olaf Leheta, Joachim K. Kraus, Dimitris Zevgaridis: A prospective randomized comparison of rectangular titanium cage fusion and iliac crest autograft fusion in patients undergoing anterior cervical discectomyJ Neurosurg Spine 4:1-9, 2006

17. Agrillo U, Mastronardi L, Puzzilli F: Anterior cervical fusion with carbon fiber cage containing coralline hydroxyapatite: preliminary observations in 45 consecutive cases of softdisc herniation. J Neurosurg 96 (3 Suppl):273-276, 2002

18. Al-Hami S (1999) Cervical monosegmental interbody fusion using titanium implants in degenerative, intervertebral disc disease. Minim Invasive Neurosurg 42:10-17

19. Palit M, Schofferman J, Goldthwaite N, Reynolds J, Kerner M, Keaney D, Lawrence-Miyasaki L (1999) Anterior discectomy and fusion for the management of neck pain. Spine 24:2224- 2228

20. Nambiar M, Phan K, Cunningham JE, Yang Y, Turner PL, Mobbs R. Locking stand-alone cages versus anterior plate constructs in single-level fusion for degenerative cervical disease: a systematic review and meta-analysis. Eur Spine J 2017;26:2258-66.

21. Chen Y, Lu G, Wang B, Li L, Kuang L. A comparison of anterior cervical discectomy and fusion (ACDF) using self- 
locking stand-alone polyetheretherketone (PEEK) cage with ACDF using cage and plate in the treatment of threelevel cervical degenerative spondylopathy: a retrospective study with 2-year follow up. Eur Spine J 2016;25: 2255-62.

22. Gercek E, Arlet V, Delisle J, Marchesi D. Subsidence of stand-alone cervical cages in anterior interbody fusion: warning. Eur Spine J 2003;12:513-6.

23. Healy AT, Sundar SJ, Cardenas RJ, et al. Zero-profile hybrid fusion construct versus 2-level plate fixation to treat adjacent-level disease in the cervical spine. J Neurosurg Spine 2014;21:753-60.

24. Yan B, Nie L. Clinical comparison of zero-profile interbody fusion device and anterior cervical plate interbody fusion in treating cervical spondylosis. Int J Clin Exp Med 2015;8:13854-8.

25. Dong J, Lu M, Lu T, et al. Meta-analysis comparing zeroprofile spacer and anterior plate in anterior cervical fusion. PLoS One 2015;10:e0130223.

26. Nemoto O, Kitada A, Naitou S, Tachibana A, Ito Y, Fujikawa A. Stand-alone anchored cage versus cage with plating for single-level anterior cervical discectomy and fusion: a prospective, randomized, controlled study with a 2-year follow-up. Eur J Orthop Surg Traumatol 2015;25:S12734.

27. Tabaraee E, Ahn J, Bohl DD, et al. Comparison of surgical outcomes, narcotics utilization, and costs after an anterior cervical discectomy and fusion: standalone cage versus anterior plating. Clin Spine Surg 2017;30:E1201-5.

28. Cao L, Chen $Q$, Jiang LB, et al. Bioabsorbable selfretaining $\mathrm{PLA} /$ nano-sized ${ }^{2}$-TCP cervical spine interbody fusion cage in goat models: an in vivo study. Int $\mathrm{J}$ Nanomedicine 2017; 12:7197-205.

29. Park JB, Cho YS, Riew KD. Development of adjacentlevel ossification in patients with an anterior cervical plate. J Bone Joint Surg Am 2005;87:558-63.

30. Fengbin Y, Xinwei W, Haisong Y, Yu C, Xiaowei L, Deyu C. Dysphagia after anterior cervical discectomy and fusion: a prospective study comparing two anterior surgical approaches. Eur Spine J 2013;22:1147-51.

31. Olsson EC, Jobson M, Lim MR. Risk factors for persistent dysphagia after anterior cervical spine surgery. Orthopedics 2015;38:e319-23.

32. Li Z, Wang H, Li L, Tang J, Ren D, Hou S. A new zeroprofile, stand-alone Fidji cervical cage for the treatment of the single and multilevel cervical degenerative disc disease. J Clin Neurosci 2017;41:115-22.

33. Lee MJ, Bazaz R, Furey CG, Yoo J. Influence of anterior cervical plate design on dysphagia: a 2-year prospective longitudinal follow-up study. J Spinal Disord Tech 2005;18:406-9.

34. Son DK, Son DW, Kim HS, Sung SK, Lee SW, Song GS. Comparative study of clinical and radiological outcomes of a zero-profile device concerning reduced postoperative dysphagia after single level anterior cervical discectomy and fusion. J Korean Neurosurg Soc 2014;56:103-7.

35. Fountas KN, Kapsalaki EZ, Nikolakakos LG, et al. Anterior cervical discectomy and fusion associated complications. Spine 2007;32:2310-7.

36. Kao TH, Wu CH, Chou YC, Chen HT, Chen WH, Tsou HK. Risk factors for subsidence in anterior cervical fusion with stand-alone polyetheretherketone (PEEK) cages: a review of 82 cases and 182 levels. Arch Orthop Trauma Surg 2014;134:1343-51.

37. Choi MK, Kim SB, Park CK, Kim SM. Comparison of the clinical and radiologic outcomes obtained with singleversus two-level anterior cervical decompression and fusion using stand-alone PEEK cages filled with allograft. Acta Neurochir 2016;158:481-7.

38. Schmieder K, Wolzik-Grossmann M, Pechlivanis I, Engelhardt M, Scholz M, Harders A. Subsidence of the wing titanium cage after anterior cervical interbody fusion: 2-year follow-up study. J Neurosurg Spine 2006;4:44753.

39. Oh JK, Kim TY, Lee HS, et al. Stand-alone cervicalcages versus anterior cervical plate in 2-level cervical anterior interbody fusion patients: clinical outcomes and radiologic changes. J Spinal Disord Tech 2013;26:415-20.

40. Zajonz D, Franke AC, von der Hoh N, et al. Is the radiographic subsidence of stand-alone cages associated with adverse clinical outcomes after cervical spine fusion?: an observational cohort study with 2-year follow-up outcome scoring. Patient Saf Surg 2014;8:43.

41. Wang Z, Jiang W, Li X, et al. The application of zeroprofile anchored spacer in anterior cervical discectomy and fusion. Eur Spine J 2015;24:148-54.

42. Zhou J, Li X, Dong J, et al. Three-level anterior cervical discectomy and fusion with self-locking standalone polyetheretherketone cages. J Clin Neurosci 2011;18:1505-9.

43. Wu WJ, Jiang LS, Liang Y, Dai LY. Cage subsidence does not, but cervical lordosis improvement does affect the long-term results of anterior cervical fusion with standalone cage for degenerative cervical disc disease: a retrospective study. Eur Spine J 2012;21:1374-82.

44. Yang JJ, Yu CH, Chang BS, Yeom JS, Lee JH, Lee CK. Subsidence and nonunion after anterior cervical interbody fusion using a stand-alone polyetheretherketone (PEEK) cage. Clin Orthop Surg 2011;3:16-23.

45. Ji GY, Oh CH, Shin DA, et al. Stand-alone cervical cages versus anterior cervical plates in 2-level cervical anterior interbody fusion patients: analysis of adjacent segment degeneration. J Spinal Disord Tech 2015;28:E433-8.

46. Mario Cabraja*, Soner Oezdemir, Daniel Koeppen and Stefan Kroppenstedt Anterior cervical discectomy and fusion: Comparison of titanium and polyetheretherketone cages BMC Musculoskeletal Disorders 2012, 13:172 